Kretschmer V, Stangel W, Wiebecke D (eds): Transfusionsmedizin 1991/92.

Beitr Infusionsther. Basel, Karger, 1992, vol 30, pp $78-81$.

\title{
Recombinant Antigens in Viral Diagnosis
}

\author{
R. Vornhagen ${ }^{a}$, A. Baur ${ }^{b}$, G. Jahn ${ }^{b}$, W. Hinderer ${ }^{a}$, H. Nebel-Schickel ${ }^{a}$, \\ J. Horn ${ }^{a}$, H. Wolf ${ }^{c}, H .-H$. Sonneborn ${ }^{a}$ \\ a Biotest AG, Research Department, Dreieichenhain, FRG \\ b Institute for Clinical and Molecular Virology, University of Erlangen, FRG \\ ${ }^{c}$ Max von Pettenkofer Institute. Munich, FRG
}

\section{Summary}

DNA fragments coding for a variety of different viral antigens have been cloned and expressed in Escherichia coli. Selected purified recombinant antigens were used for detection of specific antibodies by means of the ELISA technique. This approach has been used for the development of four different ELISAs for the detection of HIV-and EBV-specific antibodies.

\section{Introduction}

The majority of serological tests still uses not exactly defined natural antigens from different sources to detect virus-specific antibodies. Recombinant technology is in most cases the only alternative to produce selected viral antigens in large amounts in order to enhance sensitivity/specificity or facilitate standardized differential diagnosis. One of the major problems using recombinant proteins, however, is the identification of those antigens or fragments which are useful in serological diagnosis. In the following we summarize experiments which led to the development of two different recombinant test systems for the detection of HIV- and EBV-specific antibodies.

\section{Material and Methods}

Methods which led to the recombinant constructs mentioned here as well as methods used for evaluation in Western blot and ELISA experiments have been described in detail previously $[1-4]$. 


\section{Results and Discussion}

\section{Evaluation of Recombinant HIV Antigens}

In order to evaluate the diagnostic potential of different HIV antigens DNA fragments of all HIV-1 reading frames were cloned and expressed in Escherichia coli. Selected clones were evaluated in Western blot experiments with more than 400 different sera of HIV-infected, exactly classified individuals including 9 seroconversion panels. Results obtained with two different panels of patients of different clinical stages are summarized in table 1. The only antigen which reacted with all sera was gp41/1 representing the $\mathrm{N}$-terminal region of the transmembrane protein. High reactivity was also obtained with recombinant p66 (reverse transcriptase) and p31 (integrase), while seroprevalence rates of the GAG antigens p 24 and p17 were lower and revealed a large heterogeneity. The same was true for the regulative proteins.

The identification of antigens which are reactive during the seroconversion period is also of major interest. Useful tools for the evaluation of reactivity during seroconversion are seroconversion panels, which consist of longitudinal series of plasma samples collected from a single individual before, during and after seroconversion [5]. The $\mathrm{N}$-terminal portion of the transmembrane protein ( $\mathrm{gp} 41 / 1)$ and $\mathrm{p} 24$ are the first reactive antigens while the other structural proteins are less important.

In conclusion to our data gp 41 and $\mathrm{p} 24$ are excellent antigens to ensure safe diagnosis in all stages of infection, while p66 and p31 are in addition good candidates for a recombinant confirmation assay. In very early stages of infection, however, reactivity with only one antigen, in general gp41, might be possible. In order to guarantee a safe serodiagnosis of HIV-2 infections we chemically synthesized a 492bp DNA fragment coding for the N-terminal region of HIV-2, and expressed the recombinant antigen in Escherichia coli. In ELISA experiments the purified antigen revealed strong reactivity with all HIV-2-specific sera tested so far. Using the three different recombinant anti-

Table 1 . Seroreactivity of recombinant antigens $(\%)$ in Western blot - total reactivity with two panels of sera of HIV-infected individuals

\begin{tabular}{lllllllllllll}
\hline $\mathrm{n}$ & $\mathrm{p} 17$ & $\mathrm{p} 24$ & $\mathrm{p} 66$ & $\mathrm{p} 31$ & $\mathrm{gp} 120$ & $\mathrm{gp} 41 / 1$ & $\mathrm{gp41/2}$ & nef & vif & tat & rev & vpu \\
\hline 64 & 26 & 39 & 98 & 88 & 25 & 100 & 38 & 8 & 36 & 3 & 64 & 15 \\
58 & 44 & 71 & 98 & 79 & 43 & 100 & 56 & 34 & 7 & 9 & 41 & 31 \\
\hline
\end{tabular}


gens gp41 and p24 (HIV-1) and gp35 (HIV-2) we were able to develop the Biotest HIV-1/-2 recombinant ELISA, which reveals excellent sensitivity and specificity.

Development of a New EBV-ELISA System Using Recombinant Antigens Approximately $90 \%$ of the adult population are infected by EpsteinBarr virus (EBV). Although primary infections with EBV are in general asymptomatic they lead, in some cases, to a clinical syndrome called infectious mononucleosis (morbus Pfeiffer, kissing disease). EBV is also closely associated with two malignancies, i.e. nasopharyngeal carcinoma and Burkitt's lymphoma, and may be reactivated in immunosuppressed patients. There is also an increasing demand for EBV-negative blood in order to avoid complications in transplantation medicine. In previous studies recombinant antigens were identified which ensure a safe serological diagnosis in all types of EBV infection $[3,4,6,7]$. These data led to the development of a set of three ELISAs; the technical data of the recombinant antigens and the composition of the different ELISAs are summarized in table 2. In several studies $[4,7,8]$ this set of EBV-ELISAs has proven to be very useful for the diagnosis of all stages of EBV infection, and offers an excellent alternative to the time-consuming and not exactly standardized immunofluorescence techni-

Table 2. Recombinant EBV antigens and composition of Biotest anti-EBV ELISA

\begin{tabular}{llll}
\hline & Protein & & \\
\cline { 2 - 4 } & p54 & p138 & p72 \\
\hline Reading frame & BMRF 1 & BALF 2 & BKRF 1 \\
Classification & $\begin{array}{l}\text { Early antigen } \\
\text { (EA-D) }\end{array}$ & $\begin{array}{l}\text { Early antigen } \\
\text { (major DNA-binding } \\
\text { protein) }\end{array}$ & $\begin{array}{l}\text { Nuclear antigen } \\
\text { (EBNA-1) }\end{array}$ \\
Construction & $\begin{array}{l}\text { Whole coding } \\
\text { region }\end{array}$ & $\begin{array}{l}\text { Fusion of two } \\
\text { fragments }\end{array}$ & $\begin{array}{l}\text { C-terminal part } \\
(42.7 \%)\end{array}$ \\
Size of expression & $52 / 47$ & 39 & 46 \\
protein, kD & - & - & \\
\hline ELISA IgM & - & $\bullet$ & \\
\hline EA IgG & $\bullet$ & & \\
\hline EBNA IgG & & & \\
\hline
\end{tabular}


ques which are routinely used in EBV diagnosis. In addition, the ELISA system shows no interference with anticellular antibodies, and a general pretreatment of sera prior to evaluation of specific IgM antibodies in order to remove rheumatoid factors is not necessary. These findings show that the recombinant EBV-ELISAs enable easy and standardized performance of EBV serodiagnosis.

In general the preparation of viral antigens by the means of recombinant technology results in an improvement of sensitivity and specificity of serological diagnosis of viral infections. Utilization of selected recombinant antigens allows the safe identification of the different stages of viral infections.

\section{References}

1 Vornhagen R, et al: Biotest Bull 1990;4:91-96.

2 Vornhagen R, et al: in Schauzu M (ed): Progress in AIDS Research in the Federal Republic of Germany. München, MMV, 1990, pp 267-273.

3 Motz M, et al: Gene 1986;42:303-312.

4 Hinderer W, et al: Biotest Bull 1990;4:141-146.

5 Schumacher RT, et al: J Clin Immunoassay 1988;11:130-134.

6 Wolf H, et al: in Levine PH, et al (eds): Developments in Medical Virology, vol 1, Epstein-Barr Virus and Associated Diseases. Boston, 1985, pp 485-494.

7 Gorgievski-Hrisoho M, et al: J Clin Microbiol 1990;28:2305-2311.

8 Wutzler P: Biotest Bull 1991;4:325-328.

Dr. R. Vornhagen

Biotest AG

Forschung Diagnostik

Landsteinerstr. 5

W-6072 Dreieich (FRG) 